\title{
Porta Heptis
}

National Cancer Institute

\section{Source}

National Cancer Institute. Porta Heptis. NCI Thesaurus. Code C133751.

A transverse fissure on the visceral surface of the liver between the caudate and quadrate lobes, lodging the portal vein, hepatic artery, hepatic nerve plexus, hepatic ducts, and lymphatic vessels. 